\title{
The impact of four harvesting techniques on the cell viability and osteogenic behaviour of cells in autogenous bone grafts: $A$ critical appraisal of an experimental study
}

\begin{tabular}{|c|c|}
\hline $\begin{array}{l}\text { Authors: } \\
\text { Andre W. van } \\
\text { Johan Hartsh } \\
\text { Alonso Carras }\end{array}$ & $\begin{array}{l}\mathrm{Zyl}^{1} \\
\mathrm{rne}^{1,2} \\
\text { co-Labra }\end{array}$ \\
\hline \multicolumn{2}{|c|}{$\begin{array}{l}\text { Affiliations: } \\
{ }^{1} \text { Department of Periodontics } \\
\text { and Oral Medicine, University } \\
\text { of Pretoria, South Africa. }\end{array}$} \\
\hline \multicolumn{2}{|c|}{$\begin{array}{l}{ }^{2} \text { Private practice, Tyger } \\
\text { Valley, South Africa }\end{array}$} \\
\hline \multicolumn{2}{|c|}{$\begin{array}{l}{ }^{3} \text { Department of Oral and } \\
\text { Maxillofacial Surgery and } \\
\text { Evidence-Based Dentistry } \\
\text { Unit, Universidad de Chile, } \\
\text { Chile }\end{array}$} \\
\hline \multicolumn{2}{|c|}{$\begin{array}{l}{ }^{4} \text { Department of Clinical, } \\
\text { Epidemiology and } \\
\text { Biostatistics, McMaster } \\
\text { University, Canada }\end{array}$} \\
\hline \multicolumn{2}{|c|}{$\begin{array}{l}\text { Correspondence to: } \\
\text { Johan Hartshorne }\end{array}$} \\
\hline \multicolumn{2}{|c|}{$\begin{array}{l}\text { Email: } \\
\text { jhartshorne@kanonberg.co.za }\end{array}$} \\
\hline \multicolumn{2}{|c|}{$\begin{array}{l}\text { Postal address: } \\
\text { PO Box } 6223 \text {, Welgemoed } \\
7538 \text {, South Africa }\end{array}$} \\
\hline \multicolumn{2}{|c|}{$\begin{array}{l}\text { How to cite this article: } \\
\text { Van Zyl A, Hartshorne J, } \\
\text { Carrasco-Labra A. The impact } \\
\text { of four harvesting techniques } \\
\text { on the cell viability and } \\
\text { osteogenic behaviour of cells } \\
\text { in autogenous bone grafts: } \\
\text { A critical appraisal of an } \\
\text { experimental study, Open J } \\
\text { Implant Dent. 2013;1(1), Art. } \\
\# 6,3 \text { pages. http://dx.doi. } \\
\text { org/10.4102/ojid.v1i1.6 }\end{array}$} \\
\hline \multicolumn{2}{|c|}{$\begin{array}{l}\text { Copyright: } \\
\text { (C) 2013. The Authors. } \\
\text { Licensee: AOSIS } \\
\text { OpenJournals. This work } \\
\text { is licensed under the } \\
\text { Creative Commons } \\
\text { Attribution License. }\end{array}$} \\
\hline \multirow[b]{2}{*}{ Read online: } & \\
\hline & $\begin{array}{l}\text { Scan this QR } \\
\text { code with your } \\
\text { smart phone or } \\
\text { mobile device } \\
\text { to read online. }\end{array}$ \\
\hline
\end{tabular}

Authors:

Johan Hartshorne ${ }^{1,2}$

Affiliations:

${ }^{1}$ Department of Periodontics and Oral Medicine, University of Pretoria, South Africa.

${ }^{2}$ Private practice, Tyge

Valley, South Africa

${ }^{3}$ Department of Oral and Unit, Universidad de Chile,

Epidemiology and

Biostatistics, McMaster

niversity, Canada

Correspondence to:

Email:

Postal address:

PO Box 6223, Welgemoed

7538, South Africa

How to cite this article: Van Zyl A, Hartshorne J, Carrasco-Labra A. The impact on the cell viability and osteogenic behaviour of cells in autogenous bone grafts: A critical appraisal of an experimental study, Open J plant Dent. 2013;1(1), Art. \#6, 3 pages. http://dx.doi.

\section{Copyright:}

(C) 2013. The Authors.

mobile device

to read online.
The investigators tested the null hypothesis that there would be no differences between the different bone harvesting techniques with regard to cell viability, cell activity and osteogenic potential of grafted cells. Bone grafts were harvested from the mandibles of 12 miniature pigs using four different harvesting techniques: bone milling, bone scraping, bone drilling (bone slurry) and piezosurgery. Cell viability was determined according to an immunoassay of released signalling molecules and gene expression that affect bone formation and resorption. The osteogenic activity of conditioned graft-sampled media was assessed in a bioassay using isolated bone cells. Cells in autogenous bone grafts obtained by using a bone mill and a bone scraper showed a higher viability and a stronger osteogenic potential than those from piezosurgery and bone drilling (slurry). This study contributed towards the understanding of the impact of harvesting techniques on the viability and osteogenic behaviour of grafted cells.

\section{Focus article}

Miron RJ, Gruber R, Hedbom E, Saulaccic N, Zhang Y, Sculean A, Bosshardt DD, Buser D. Impact of bone harvesting techniques on cell viability and the release of growth factors of autografts. Clinical Implant Dentistry and Related Research. 2012, DOI 10.1111/j1708-8208.2012.00440.x

\section{Introduction}

Autogenous bone grafts are considered to be the 'gold standard' for bone grafting in alveolar bone augmentation procedures and treatment of bone defects because of the presence of viable cells and growth factors that enhance bone growth. There is a paucity of information on why and how bone grafts obtained by different harvesting techniques behave differently during the process of wound healing and graft consolidation. The purpose of this in vitro experimental study was to establish the effect of different bone harvesting techniques on the biological viability, activity (release of growth factors and other bioactive molecules) and osteogenic potential of transplanted cells that contribute to the process of graft consolidation and subsequent bone formation. Knowledge of cellular behaviour and activity may assist clinicians in selecting the most appropriate harvesting technique for obtaining autogenous bone grafts with the best osteogenic potential, thus ultimately contributing towards a successful therapeutic outcome.

\section{Appraisal of study methodology and validity of the results}

Bone grafts were obtained from 12 sedated miniature pigs. The Ethical Committee for Animal Research, State of Bern, Switzerland approved the protocol. To minimise selection bias, increase the strength (precision) of the treatment effect, reduce the number of animals used and optimise efficient use of resources, bone grafts were obtained from the lateral portion of the mandible during each harvesting technique. Each graft site was subdivided into four sections for collecting cells using four different techniques:

- Corticocancellous block grafts were harvested with a $6 \mathrm{~mm}$ trephine and ground to particulate bone chips using a bone mill.

- Bone chips were harvested with a sharp bone scraper.

- Bone particles were collected with a bone trap filter from the suction tip after drilling of cortical bone with a $2.2 \mathrm{~mm}$ round bur under saline conditions (bone slurry).

- Bone particles were harvested with a piezosurgery device under saline conditions.

Harvested grafts were all treated equally to minimise contamination and transportation for in vitro experiments. 
For each grafted sample, bone particle size was determined using light microscopy and the surface variation was assessed using scanning electron microscopy. The number of viable cells in autogenous bone particles was determined by bioassay. Three independent experiments were performed for each harvesting method and all samples were measured in duplicate. Data $( \pm \mathrm{SE})$ were normalised to bone mill samples. Cell activity was determined by measuring the growth factors and gene expression affecting bone formation and resorption, namely bone morphogenic protein-2 (BMP2), transforming growth factor $\beta 1$ (TGF $\beta 1$ ), vascular endothelial growth factor (VEGF), osteoprotegerin (OPG) and receptor activator of nuclear factor kappa B ligand (RANKL) using immunoassay techniques. Conditioned media prepared with various harvested autogenous bone samples were incubated with primary bone cells to determine the osteogenic potential and translation of cell viability and gene expression into paracrine function to form new bone.

Appropriate statistical analyses were conducted and mean values $( \pm S E)$ were reported. The data were analysed for statistical significance using analysis of variance tests. Sufficient information was included in the scientific publication to ensure that the methods could be repeated. Figures were provided instead of raw data for cell activity and osteogenic potential, making it difficult to review and analyse the results. This study was conducted according to high standards of scientific rigour with regard to experimental design and methodology and transparency of reporting. Therefore there is no reason to believe that there is a threat to the internal validity of the results. This study satisfied all the internal validity assessment criteria. The results therefore likely yielded an accurate, transparent and unbiased assessment of the treatment effect.

The study was supported by a grant from the International Team for Implantology Foundation. The authors declared no conflicts of interest.

\section{Results}

Bone chips harvested by bone milling $(1.551 \mathrm{~mm} \pm 0.137 \mathrm{~mm})$ and bone scraping $(1.805 \mathrm{~mm} \pm 0.154 \mathrm{~mm})$ were larger than the graft particles obtained from piezosurgery (1.352 $\mathrm{mm} \pm 0.070 \mathrm{~mm}$ ) and bone drilling (bone slurry) $(0.215 \mathrm{~mm} \pm 0.010 \mathrm{~mm})$. Scanning electron microscopy showed collagen fibres on the surface of bone chips obtained by bone milling. The number and activity of viable cells in autogenous bone chips obtained by bone milling and bone scraping were significantly greater compared to that in cells obtained from bone slurry and piezosurgery.

Bioactive molecules and gene expression of growth factors related to bone formation (BMP2, VEGF, and TGF 31 ) were significantly higher in autogenous bone chips harvested by bone mill and bone scraper compared to the other grafting modalities. In contrast, the bioactive molecules and gene expression for RANKL, a biomolecule that is associated with bone resorption, was significantly lower in autogenous bone chips obtained with a bone scraper (indicating less resorption) and significantly higher in bone slurry particles obtained from bone drilling, thus indicating a higher resorption rate.
The relative proliferation rates and osteogenic potential were significantly greater with the conditioned-media samples of autogenous bone chips from bone milling and bone scraping. Samples obtained by means of piezosurgery and bone slurry showed significantly less osteogenic potential.

\section{Discussion}

Although controversial in its applicability, experiments using animal models are traditionally used to investigate physiologic processes and the efficacy and safety of therapeutic procedures or agents. The debate, however, continues whether the insights yielded by animal studies can be applied to humans. For scientific, economic and ethical reasons, miniature pigs are commonly used as a large animal model in experimental dental studies. The similarities between the oral maxillofacial region of miniature pigs and that of humans with regard to anatomy, development, physiology, pathophysiology and disease occurrence also render these animals appropriate models for research. ${ }^{1}$

Despite the scientific rigour of the current study, extrapolating the results to humans should be approached with caution. The results did, however, provide valuable knowledge that will enhance our understanding of the effect of harvesting techniques on the viability and osteogenic behaviour of grafted cells. There is no compelling reason why the knowledge gained from this study cannot be used to assist clinicians when deciding on the harvesting technique to be used and the type of instruments or equipment to be purchased. The knowledge yielded by this study may contribute towards successful therapeutic outcomes in bone grafting procedures and pave the way for further preclinical and clinical research.

\section{Conclusion Clinical implications}

This study provided a model to better understand the biologic trends in bone behaviour and the osteogenic potential of autogenous bone obtained by four different harvesting methods. The authors concluded that cells in autogenous bone grafts obtained using a bone mill or a bone scraper showed a higher viability and a stronger osteogenic potential than cells obtained by means of piezosurgery or bone drilling (slurry). Overheating during mechanical harvesting, such as occurs in bone slurry preparations, or vibrations generated during piezosurgery harvesting could potentially affect cell viability. Osteogenesis also occurred more rapidly in bone chips than in bone sludge.

The investigators based their assumptions on the observation that growth factors released from grafted cells may contribute towards graft consolidation. If this assumption is true, autogenous bone harvested by bone milling or bone scraping might be more favourable than grafts harvested by means of piezosurgery or bone drilling.

\section{Limitations}

Animal characteristics (strain, weight, sex and age) were not provided. These are important variables as they could 
potentially affect the precision of the results. The investigators did not report whether a power analysis was performed to determine the sample size. This is important for detecting a biologically important effect if present, or to prevent animals being used unnecessarily. The investigators did not report whether assessors were blinded to minimise bias with outcome assessment. Measurements that are conducted blind are more likely to produce accurate (precise) results or estimates of treatment efficacy. The authors did not report the $p$-values and statistical significance.

Cell viability and gene expression in in vitro experiments remain surrogate measures to predict the biologic process of graft consolidation and the associated therapeutic success of bone grafting procedures. Further research in humans is required to lend credibility to these results.

\section{Research gaps}

Further preclinical research is required on the cellular composition of bone graft samples and its effect on gene expression. Biomechanical stresses induced by the different harvesting techniques may result in a change in cell population and thus influence cellular response and gene expression. The effect of mechanical harvesting and piezosurgery on the biological processes of bone resorption also requires further investigation.
Well-designed clinical trials are needed to determine which autogenous bone harvesting techniques are the most effective for specific clinical indications with reference to treatment time, cost of resources, clinical outcome of graft consolidation and complications associated with bone grafts and harvest sites.

\section{Acknowledgement}

AOSIS is thanked for contributing towards the copyediting and publishing costs of this article.

\section{Competing interests}

The authors declare that they have no financial or personal relationship(s) that may have inappropriately influenced them in writing this article.

\section{Authors' contributions}

J.H. was the project leader. A.v.Z., J.H. and A.C-L. made conceptual contributions to the methodological quality and synthesis of the study within the relevant clinical context.

\section{Reference}

1. Wang S, Liu Y, Fang D, Shi S. The miniature pig: A useful animal model for dental and orofacial research. Oral Dis. 2007;13(6):530-537. http://dx.doi.org/10.1111/ j.1601-0825.2006.01337.x, PMid:17944668 